\title{
Differential actions of proteinases and neuraminidase on mammalian erythrocyte surface and its impact on erythrocyte agglutination by concanavalin $\mathrm{A}$
}

\author{
Savita Sharma and Sadashiv M. Gokhale \\ School of Biochemistry, Devi Ahilya University, Khandwa Road, Indore 452017, India
}

\begin{abstract}
Action of proteinases viz. trypsin and chymotrypsin, and neuraminidase on intact erythrocyte membrane proteins and glycophorins (sialoglycoproteins) exposed to cell surface and its impact on lectin (concanavalin A)-mediated agglutination were studied in Homo sapiens (human), Capra aegagrus hircus (goat) and Bubalus bubalis (buffalo). Membrane proteins and glycophorins analysis by SDS-PAGE as visualized by coomassie brilliant blue and periodic acid-schiff stains, respectively, and agglutination behaviour revealed marked differences: 1 ) there were prominent dissimilarities in the number and molecular weights of glycophorins in human, goat and buffalo erythrocyte membranes; 2 ) proteinase action(s) on human and buffalo erythrocyte surface membrane proteins and glycophorins showed similarity but was found different in goat; 3) significant differences in erythrocyte agglutinability with concanavalin A can be attributed to differences in membrane composition and alterations in the surface proteins after enzyme treatment; 4) a direct correlation was found between degradation of glycophorins and concanavalin A agglutinability; 5) action of neuraminidase specifically indicated the negative role of cell surface sialic acids in determining concanavalin A agglutinability of goat and buffalo erythrocytes, similar to human. Present studies clearly indicate that there are some basic differences in human, goat and buffalo erythrocyte membrane proteins, especially with respect to glycophorins, which determine the concanavalin A-mediated agglutination in enzyme treated erythrocytes.
\end{abstract}

Key words: Erythrocyte membrane proteins - Glycophorins - Proteinases - Neuraminidase - Agglutination

\section{Introduction}

The human erythrocyte membrane surface has proteinase-cleavage sites located within the external domain of susceptible membrane polypeptides (Dzandu et al. 1985; Gokhale and Mehta 1987a; Hamasaki et al. 1997; Ali and Tayyab 2001; Rashid et al. 2001). A carboxyl-terminal fragment of the band 3 molecule is generated by digestion with chymotrypsin at the external face of intact erythrocytes (Markowitz and Marchesi 1981) and the cleaved fragments are retained within the membrane, while trypsin has no action on erythrocyte membrane proteins. It causes diges-

Correspondence to: Sadashiv M. Gokhale, School of Biochemistry, Devi Ahilya University, Khandwa Road, Indore 452017, India

E-mail: gokhale.drsm@gmail.com tion of glycophorins viz. PAS-1 (glycophorin A dimer) and PAS-2 (glycophorin A monomer) bands. Glycophorins are sialoglycoproteins (sialic acid rich glycoproteins) and neuraminidase releases sialic acid ( $\mathrm{N}$-acetyl neuraminic acid) from glycophorins which decreases the cell surface charge (Gahmberg and Andersson 1982). Proteinases also modify several membrane proteins of bovine, equine and porcine erythrocytes (Makino et al. 1984; Moriyama et al. 1994; Okamura et al. 2007).

As a consequence of alterations occurring in the membrane, cells acquire a high agglutinability with plant lectins (Abu et al. 1963; Anderson et al. 2002). Extensive studies have been undertaken to elucidate the basis of the high lectin-agglutinability and several factors that influence the agglutinability of cells have been identified (Nicolson 1976; Mehta et al. 1988; Pestonjamasp and Mehta 1991). The major factors responsible for agglutination 
are the number and characteristics of the lectin receptors, the cell-surface charge as determined by sialic acid residues, the mobility of the lectin-receptor complexes in the membrane and the mobility-modulating agents such as cytoskeletal elements, and cellular deformability. A considerable amount of information is available on the concanavalin A (Con A)-mediated agglutination of human erythrocytes after treatment with proteolytic enzymes (Nicolson 1976; Gokhale and Mehta 1987a,b,c), as found in normal nucleated cells (Burger 1970). Presence of sialic acid on glycophorins, especially glycophorin A of erythrocytes appears to be responsible for inhibition of agglutination with Con A (Gokhale and Mehta 1987a). Thus, human erythrocytes offer detailed information of the possible factors which affect agglutination. Band 3 has been identified as Con A receptor in human erythrocytes (Kapito and Lodish 1985). Some factors responsible for Con A-agglutinability of animals like sheep, and rabbit erythrocytes have been reported. Treatments with trypsin and neuraminidase cause the agglutination of rabbit erythrocytes but had almost no effect on sheep erythrocytes (Haskovec and Kinkor 1976). In the present study, we analyzed the actions of proteinases and neuraminidase on erythrocyte surface of two economically important mammals (goat and buffalo) and compared them with that of human and their impact on animal erythrocyte agglutination by Con $\mathrm{A}$.

\section{Materials and Methods}

L-1-tosylamido-2-phenylethyl chloromethyl ketone (TPCK)-trypsin, Tosyl-L-lysine chloromethyl ketone (TLCK)-chymotrypsin, neuraminidase (type VI-from Clostridium perfringens), Con A (IV), sodium dodecyl sulfate, phenylmethylsulfonyl fluoride (PMSF), N,N'-methylene bisacrylamide, N,N,N'N'-tetramethylethylenediamine and coomassie brilliant blue R-250 were the products of Sigma Chemical Co., St. Louis, MO, USA. All other chemicals were analytical research grade.

\section{Preparation of erythrocytes}

Human blood was obtained from healthy donors of Devi Ahilya University, Indore, India. Goat and buffalo blood of healthy animals was obtained from local slaughter houses. All blood samples were collected in acid citrate dextrose (anticoagulant) solution. Erythrocytes were obtained by removing plasma and buffy coat from blood by centrifugation at $1000 \times g$ for $5 \mathrm{~min}$ at room temperature and further washed with 10 volumes of cold Tris buffered saline (TBS; $0.01 \mathrm{M}$ Tris- $\mathrm{HCl}$ buffer, $\mathrm{pH} 7.4$ containing $150 \mathrm{mM} \mathrm{NaCl}$ ) four times at $1000 \times g$ value.

\section{Enzyme treatment of erythrocytes}

One volume $(1 \mathrm{ml})$ of washed erythrocytes $(100 \%$ hematocrit/ packed cells) were suspended in two volumes $(2 \mathrm{ml})$ of the enzyme solution (trypsin, chymotrypsin or neuraminidase), gently stirred and incubated at $37^{\circ} \mathrm{C}$ for $90 \mathrm{~min}$. The trypsin $(100 \mu \mathrm{g} / \mathrm{ml})$ and chymotrypsin $(250 \mu \mathrm{g} / \mathrm{ml})$ were prepared in TBS. Neuraminidase was dissolved in 0.1 $\mathrm{M}$ Tris-maleate buffer, pH 5.6 containing $0.11 \mathrm{M} \mathrm{NaCl}$. After incubation, the cells were washed four times with at least ten volumes of chilled TBS (Gokhale and Mehta 1987a).

\section{Membrane preparation}

Membranes were prepared from buffer and enzyme-treated erythrocytes according to Hanahan and Ekholm (1974) with the addition of $1 \mathrm{mM}$ PMSF. Washed erythrocytes were lysed by mixing with 30 volumes of cold $0.01 \mathrm{M}$ Tris- $\mathrm{HCl}$ buffer, $\mathrm{pH}$ 7.4. After $15 \mathrm{~min}$ in cold, the suspension was centrifuged at $22,000 \times g$ for $15 \mathrm{~min}$ in a refrigerated centrifuge at $4^{\circ} \mathrm{C}$. The resulting deep red supernatant was discarded. The small opaque button seen below the translucent pellet of membranes was carefully removed. The membranes were suspended in $0.01 \mathrm{M}$ Tris- $\mathrm{HCl}$ buffer, $\mathrm{pH} 7.4$ and re-centrifuged. In the last washing, $0.05 \%$ sodium azide $\left(\mathrm{NaN}_{3}\right)$ was added to the washing buffer to prevent microbial growth. In this way, the membranes were washed four times, until a milky white preparation was obtained.

\section{Sodium dodecyl sulfate-polyacrylamide gel electrophoresis (SDS-PAGE)}

Polyacrylamide gel electrophoresis in the presence of SDS was performed according to Laemmli (1970) with some modifications. The slab gel ( $1.5 \mathrm{~mm}$ thickness) consisted of $10 \%$ acrylamide in the running gel $(\mathrm{pH} 8.8)$ and $5 \%$ acrylamide in the stacking gel ( $\mathrm{pH} 6.8$ ). The protein concentration was determined by the procedure of Lowry et al. (1951). Protein samples were solubilized in the sample buffer to get $0.031 \mathrm{M}$ Tris, $1 \%$ SDS, $0.25 \% \beta$-mercaptoethanol and $5 \%$ glycerol in final volume and heated at $100^{\circ} \mathrm{C}$ for $10 \mathrm{~min}$ before loading on the gel. Electrophoresis was carried out at a constant current of $2 \mathrm{~mA} / \mathrm{cm}$ using electrophoresis buffer (0.025 M Tris, $0.2 \mathrm{M}$ glycine, $0.2 \% \mathrm{SDS}$ ).

\section{Staining and destaining of the gels}

After electrophoresis, gels were removed from the glass plates and processed further for staining and destaining in a washed plastic container.

Coomassie brilliant blue (CBB) staining: Before CBB staining, the gels were fixed for $30 \mathrm{~min}$ in $40 \%$ methanol-10\% acetic acid and then stained overnight in the same solution 
containing $0.1 \%(\mathrm{w} / \mathrm{v})$ CBB. Gels were destained in $40 \%$ methanol-10\% acetic acid.

Periodic acid-Schiff (PAS) staining: The carbohydratespecific staining was performed according to Fairbanks et al. (1971). SDS was removed from the gel by stirring in solution containing $25 \%$ isopropanol, $10 \%$ acetic acid for $12 \mathrm{~h}$ followed by washing with $10 \%$ acetic acid for $10 \mathrm{~h}$. The gel was then sequentially treated with staining reagents with gentle stirring at room temperature in the following order: $0.5 \%$ periodic acid for $2 \mathrm{~h} ; 0.5 \%$ sodium arsenite and 5\% acetic acid for $30 \mathrm{~min} ; 0.1 \%$ sodium arsenite, $5 \%$ acetic acid for $20 \mathrm{~min}$ and Schiff reagent for overnight. The gel was destained in $0.1 \%$ sodium metabisulphite in $0.01 \mathrm{~N} \mathrm{HCl}$ for several hours with intermittent changes, till the background became clear.

Restaining of PAS-stained gels with CBB: PAS-stained gels were restained in $0.01 \% \mathrm{CBB}$ stain for $30 \mathrm{~min}$ as described above.

\section{Gel image analysis}

The CBB and PAS-stained gels were scanned using scanner HP scanjet 7400c. Densitograms of the gel images were obtained by using the UVP Bio-Imaging Systems "LabWorks TM Image Acquisition and Analysis software, version 4.0.0.8”.

\section{Agglutination assay}

A $0.4 \%(\mathrm{v} / \mathrm{v})$ suspension of untreated (normal) or enzymetreated erythrocytes was mixed with an equal volume of the freshly prepared Con A solution in TBS at room temperature. A control containing the relevant inhibitory sugar (0.05 $\mathrm{M}$ a-methyl D-mannopyranoside) and the highest Con A concentration $(100 \mu \mathrm{g} / \mathrm{ml})$, was used in the assay. After $45 \mathrm{~min}$ incubation at $37^{\circ} \mathrm{C}$, the tubes were tapped several times and the unagglutinated cells (free or in twocelled aggregates) were counted using a hemocytometer under the microscope. The extent of agglutination was calculated as described by Gokhale and Mehta (1987a) in the following way:

$$
\text { Agglutination }(\%)=100-\left(100 \times \frac{\mathrm{n}_{\mathrm{UC}}}{\mathrm{n}_{\mathrm{IC}}}\right)
$$

where $\mathrm{n}_{\mathrm{UC}}$ is number of unagglutinated cells and $\mathrm{n}_{\mathrm{IC}}$ is number of input cells. Alternatively, the same assay was performed using microtitre plate and agglutination was judged by visual appearance of erythrocyte pellets.

\section{Statistical analysis}

The agglutination data were expressed as mean \pm standard error (S.E.M.) and were analyzed by one way analysis of variance (ANOVA) followed by a post hoc Newman-Keuls multiple comparison test using a trial version of PRISM 5 software for windows (GraphPad Software, Inc., La Jolla, CA, USA). For the statistical evaluation of the results, significance was defined by a probability level of $p<0.05$. All the experiments were carried out five times.

\section{Results}

Proteolytic action of trypsin and chymotrypsin on mammalian erythrocyte membrane proteins

To understand the action of proteinases on surface-exposed membrane proteins, the intact erythrocytes were subjected to proteolytic digestion by treatment either with trypsin or chymotrypsin. The membranes were isolated from extensively washed proteinase-treated erythrocytes and analyzed by SDS-PAGE followed by CBB stain (Fig. 1). The human erythrocyte membrane protein patterns of untreated (Fig. 1, lane 1-H) and trypsin (lane 2-H) treated erythrocytes were almost similar indicating no action of trypsin on erythrocyte surface-exposed proteins. The action of chymotrypsin on band 3 was indicated by the appearance of an intense band of molecular weight (Mr) $58 \mathrm{kDa}$ (Fig. 1, lane 3-H) (Jennings and Nicknish 1985; Gokhale and Mehta 1987a). The densitogram (Fig. 1, DS-H) also indicated the reduction in the peak intensity of band 3 and a sharp increase near the position of band 4.5, Mr $58 \mathrm{kDa}$. The results of digestion of goat erythrocytes with proteinases indicated a slight action of trypsin possibly on gp155 (Inaba and Maede 1988). Due to the action of trypsin on goat erythrocytes, three new fragments were observed with apparent Mrs of $57 \mathrm{kDa}, 48 \mathrm{kDa}$ and 37 $\mathrm{kDa}$ (Fig. 1, lane 2-G and DS-G). The high Mr fragments were more intense as compared to lower Mr protein fragments. On the other hand, chymotrypsin had no action on goat erythrocyte membrane proteins. The action of trypsin on buffalo erythrocyte membranes was found to be similar to that of human (Fig. 1, lanes 2-B and 3-B). There was no action of trypsin on buffalo erythrocyte membranes (Fig. 1, lane 2-B) but chymotrypsin showed some action indicated by the appearance of three new degradation products of $\mathrm{Mr}$ $63 \mathrm{kDa}$ (greater than band 3 fragment of human - $58 \mathrm{kDa}$ ), $50 \mathrm{kDa}$ and $37 \mathrm{kDa}$ fragments (Fig. 1, lane 3-B).

\section{Proteolytic action of trypsin and chymotrypsin on mammalian erythrocyte membrane glycophorins}

The actions of proteinases on surface-exposed glycophorins were studied by subjecting the erythrocyte membranes to SDS-PAGE followed by sialoglycoprotein-specific PAS staining (Fig. 2). In case of human erythrocytes, trypsin shows a drastic action on bands PAS- 1 and PAS- 4 while another band 
PAS-2 is partially degraded by the enzyme (Fig. 2, lane 2-H). A new fragment of $\mathrm{Mr} 62 \mathrm{kDa}$ was seen, possibly indicating the trypsin degradation product of PAS bands, retained in the membrane (Gokhale and Mehta 1987a). In chymotrypsintreated human erythrocytes (Fig. 2, lane 3-H), a decrease in the intensities of PAS-1 and PAS- 2 was observed (Gokhale and Mehta 1987a). In the case of goat erythrocytes, trypsin showed action on PAS-GI, PAS-GII and PAS-GIV bands but it had no action on other PAS bands (Fig. 2, lane 2-G). The degradation products of these glycophorins were observed with apparent Mrs of $150 \mathrm{kDa}, 100 \mathrm{kDa}, 87 \mathrm{kDa}, 65 \mathrm{kDa}, 44 \mathrm{kDa}$ and $32 \mathrm{kDa}$. In case of chymotrypsin-treated erythrocytes (lane 3-G), a drastic action was seen on PAS-GI, PAS-GII, PASGIII and PAS-GVIII bands of goat erythrocytes without any action shown on other PAS bands. The degradation products were seen in the range of PAS-GIV to PAS-GVI (99-65 kDa).
Densitogram (Fig. 2, DS-G) also showed tremendous decrease in intensities of peaks of PAS-GI and PAS-GII which was an indication of their complete degradation by chymotrypsin. In buffalo erythrocytes, the trypsin acted partially on PAS-BI and PAS-BII but extensively on PAS-BIII, PAS-BIV and PAS-BV (Fig. 2, lane 2-B). Among all the PAS bands of buffalo, PAS$\mathrm{BV}$ was observed as a long diffused zone and these findings were also noticed in the densitogram (Fig. 2, DS-B). Action of chymotrypsin on buffalo erythrocyte glycophorins was indicated by marginal shifting of PAS bands and appearance of some new bands (Fig. 2, lane 3-B).

To know the relative positions of proteins, glycophorins and their degradation products formed due to the action of proteinases on erythrocytes, the PAS-stained gel was restained with $\mathrm{CBB}$ stain (Fig. 3). This double stained gel permitted direct visualization of the positions of glycophorin
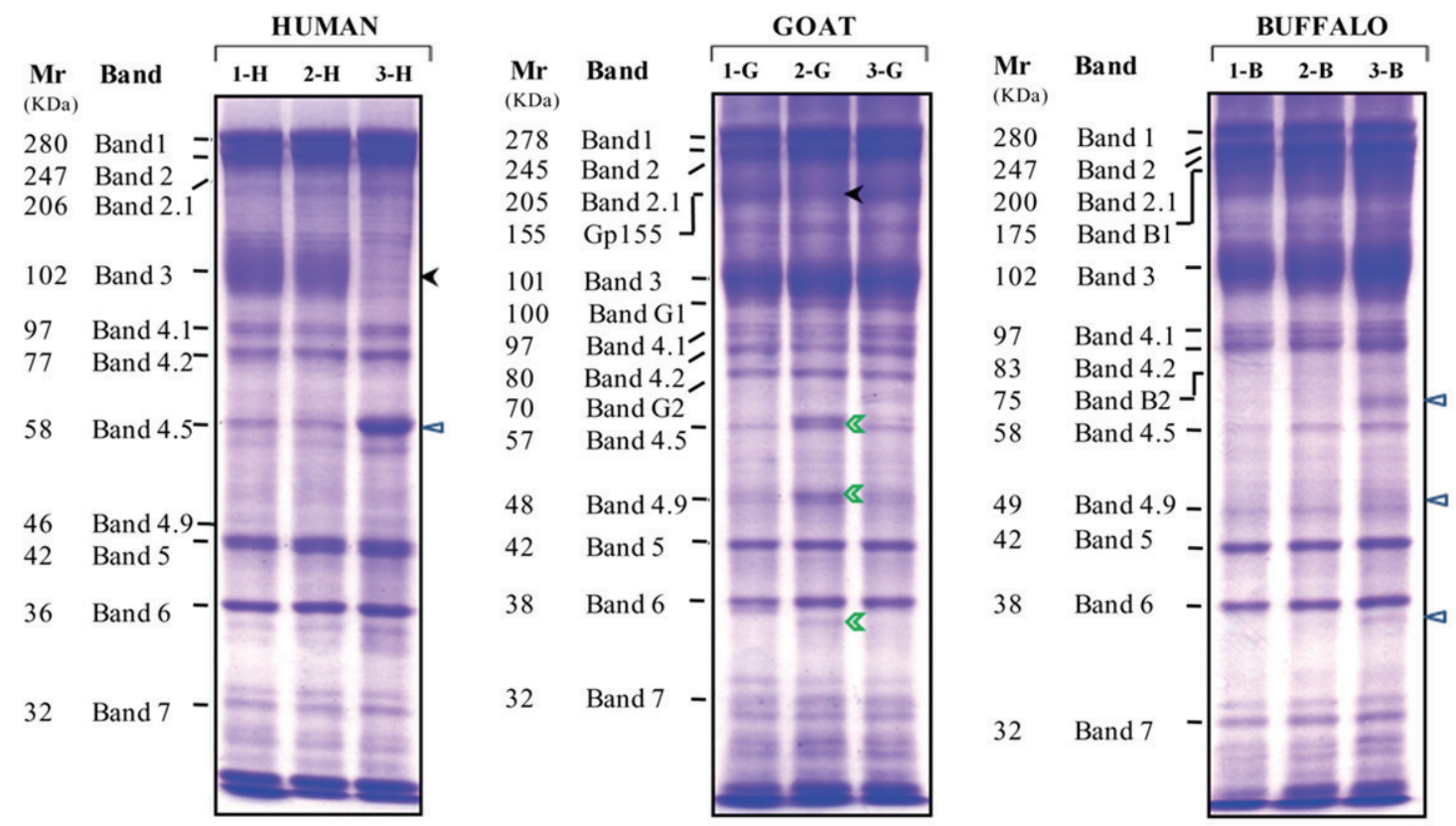

DS-H

DS-G

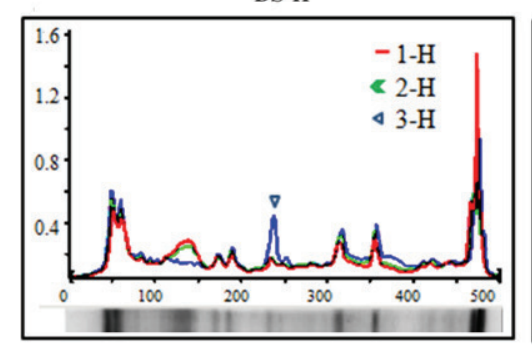

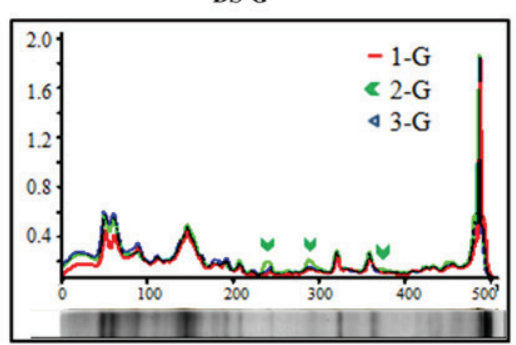

DS-B

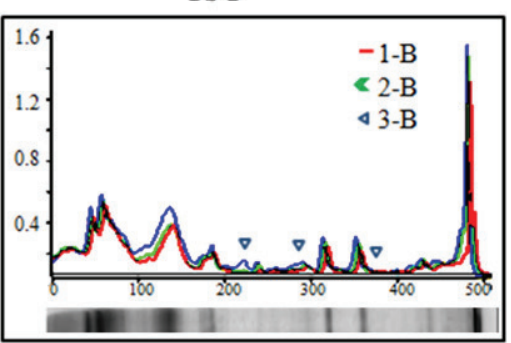

Figure 1. Analysis of membrane proteins obtained from proteinase (trypsin or chymotrypsin)-treated erythrocytes by SDS-PAGE (10\% gel) followed by CBB staining. Lane 1: untreated membranes ( $60 \mu \mathrm{g}$ protein in each lane); lane 2: trypsinized membranes (60 $\mu \mathrm{g}$ protein in each lane); lane 3: chymotrypsinized membranes (60 $\mu \mathrm{g}$ protein in each lane); DS, densitogram; H, human; G, goat; B, buffalo. (Note: $<$ arrow head indicates the protein acted upon by proteinase; $B$ and $\triangleleft$ arrows indicate the new fragments generated after trypsin and chymotrypsin actions, respectively). 
bands in relation to all other membrane protein bands. In trypsin-treated (lane 2-H) human erythrocyte membranes (Fig. 3), a new PAS-stained glycophorin fragment (62 kDa) was observed in the region of band 4.5. The new band 3 fragment generated due to chymotrypsin action was found to be present just below the PAS- 4 band. The restaining of PAS-stained gel of goat erythrocyte membrane with CBB (Fig. 3) indicated the relative positions of new glycophorin fragments formed by the action of trypsin (lane 2-G) and chymotrypsin (lane 3-G). The membrane glycophorin fragments formed with trypsin treatment were located at various positions viz. below Gp155 (155 kDa), band G1 (100 kDa), band $4.2(80 \mathrm{kDa})$, band $4.5(57 \mathrm{kDa})$, band 4.9 (48 kDa), above band $6(38 \mathrm{kDa})$ and band $7(32 \mathrm{kDa})$. The chymotrypsin-treated membrane glycophorin fragments were observed at positions of band G1 (100 kDa), band 4.2
(80 kDa), band G2 (70 kDa) and below band G2 $(67 \mathrm{kDa})$. The trypsin-degraded glycophorin fragments (in restained PAS gel with CBB stain) of buffalo erythrocyte membranes (Fig. 3, lane 2-B) were found to be present below band 6 with Mrs $37 \mathrm{kDa}$ and $34 \mathrm{kDa}$. The chymotrypsin-degraded glycophorin fragments were located above band $3(105 \mathrm{kDa})$, in the region of band $4.9(49 \mathrm{kDa})$, below band $5(41 \mathrm{kDa})$ and below band 6 with $\mathrm{Mr} 37 \mathrm{kDa}$ and $34 \mathrm{kDa}$.

\section{Neuraminidase action on erythrocyte membrane glycophorins}

Neuraminidase selectively acts on sialoglycoproteins by hydrolyzing terminal sialic acid ( $\mathrm{N}$-acetyl neuraminic acid) residues and such an action can be analyzed by sialoglycoprotein-specific PAS staining. Due to the action of neuraminidase on erythrocyte glycophorins, removal of sialic acid was
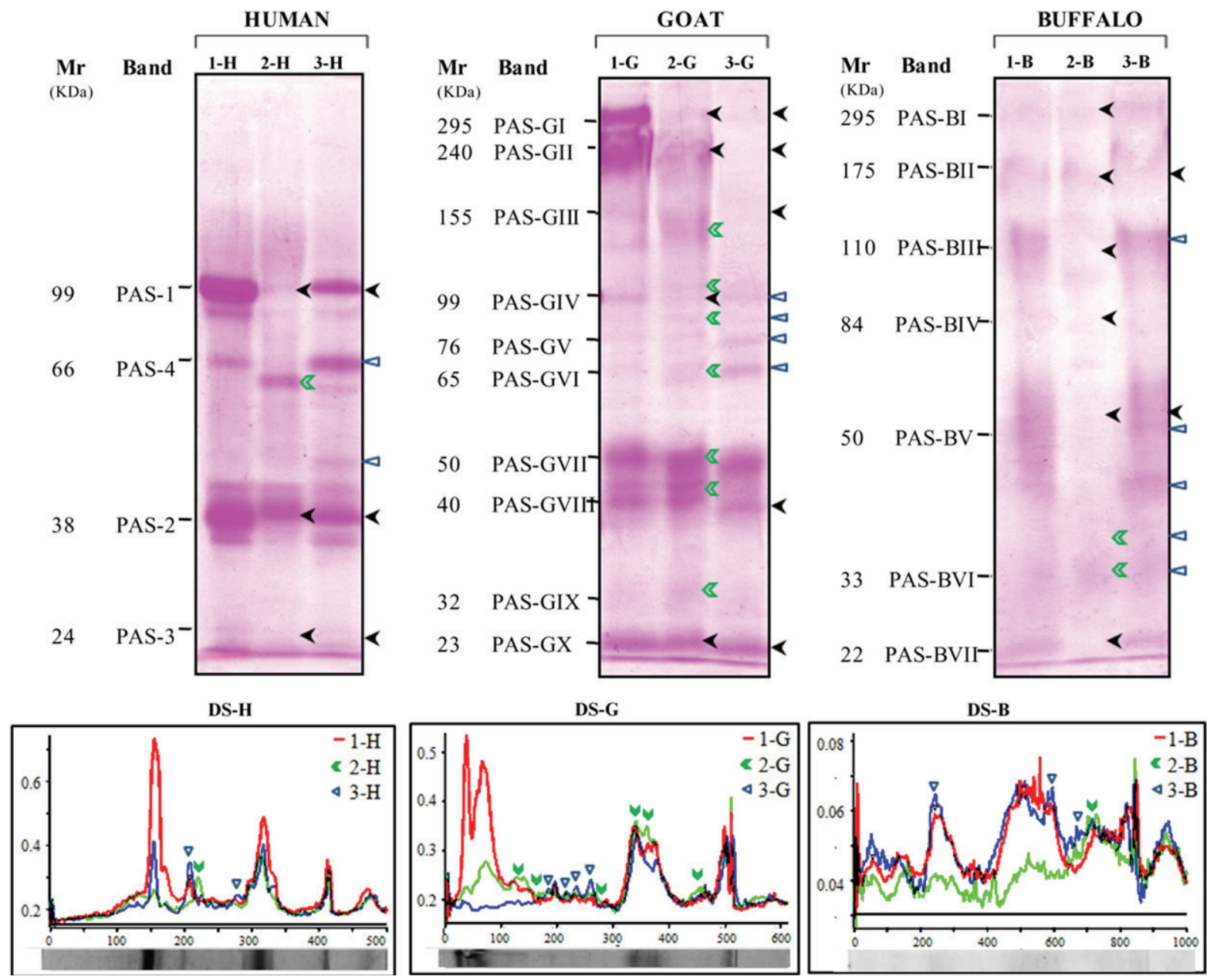

Figure 2. Analysis of membrane glycophorins obtained from proteinase (trypsin or chymotrypsin)-treated erythrocytes by SDS-PAGE (10\% gel) followed by PAS staining. Lane 1: untreated membranes (180 $\mu \mathrm{g}$ protein in each lane); lane 2: trypsinized membranes (180 $\mu \mathrm{g}$ protein in each lane); lane 3: chymotrypsinized membranes (180 $\mu$ g protein in each lane); DS, densitogram; H, human; G, goat; B, buffalo. (see: Note in legend of Figure 1). 
indicated by the shift in PAS bands on the polyacrylamide gel (Fig. 4). A remarkable action of neuraminidase on all the PAS bands of human erythrocyte membrane was observed with the appearance of new fuzz bands with Mrs $81 \mathrm{kDa}, 35 \mathrm{kDa}$ and $22 \mathrm{kDa}$ (Fig. 4, lane 2-H) as reported earlier (Gokhale and Mehta 1987a). Alteration in the position and intensity of PAS bands is very well depicted in the densitogram (Fig. 4, DS-H). In the case of goat erythrocytes, PAS-GI and PASGVII were completely degraded by neuraminidase, as no band was visible at the positions of these glycophorins while PAS-GII did not show any visible change (Fig. 4, lane 2-G). PAS-GIII, PAS-GIX and PAS-GX were partially degraded by neuraminidase as indicated by their reduced intensities. Below PAS-GVII, four new bands ( $46 \mathrm{kDa}, 43 \mathrm{kDa}, 38 \mathrm{kDa}$ and $36 \mathrm{kDa}$ ) of glycophorins were observed which can be clearly seen in the densitogram (Fig. 4, DS-G). The neuraminidase showed mild action on all the buffalo glycophorins viz. PAS-BI to PAS-BVII (Fig. 4, lane 2-B). The surprising observation about buffalo glycophorins was the upward shifts of some PAS bands viz. PAS-BIII (120 kDa) and PAS-BV (60 $\mathrm{kDa})$. Other glycophorins like PAS-BI, PAS-BII, PAS-BIV, PAS-BVI and PAS-BVII showed reduced band intensities. These observations regarding upward shifts and decrease in PAS bands' intensities were also seen in the densitogram (Fig. 4, DS-B).
Erythrocyte glycophorins are sialoglycoproteins and due to high sialic acid content they cannot be stained with $\mathrm{CBB}$ staining. Alteration in the staining property of glycophorins after removal of sialic acids by neuraminidase was also analyzed by SDS-PAGE followed by CBB staining (Fig. 5). The protein bands in the region of Mrs of $59 \mathrm{kDa}$ and $22 \mathrm{kDa}$ showed higher intensity in neuraminidase-treated human erythrocytes (lane 2-H, DS-H). The neuraminidase action on goat erythrocytes showed the higher intensity of protein bands with Mrs $90 \mathrm{kDa}, 50 \mathrm{kDa}, 32 \mathrm{kDa}$ and $21 \mathrm{kDa}$ along with an additional new band (75 kDa) (lane 2-G,DS-G). In case of buffalo erythrocytes, neuraminidase digestion showed the appearance of two new protein bands with Mrs $67 \mathrm{kDa}$ and $20 \mathrm{kDa}$ (lane 2-B, DS-B).

Relative positions of erythrocyte membrane proteins and glycophorins after neuraminidase treatment on the same gel were determined by restaining the PAS-stained gel with CBB staining (Fig. 6).

\section{Con A-mediated agglutinability of mammalian erythrocytes}

On the erythrocyte membrane surface Con A binds to band 3 (Findlay 1974), but has been found unable to agglutinate native (untreated) human erythrocytes. Only after treatment with a proteolytic enzyme or neuraminidase, the
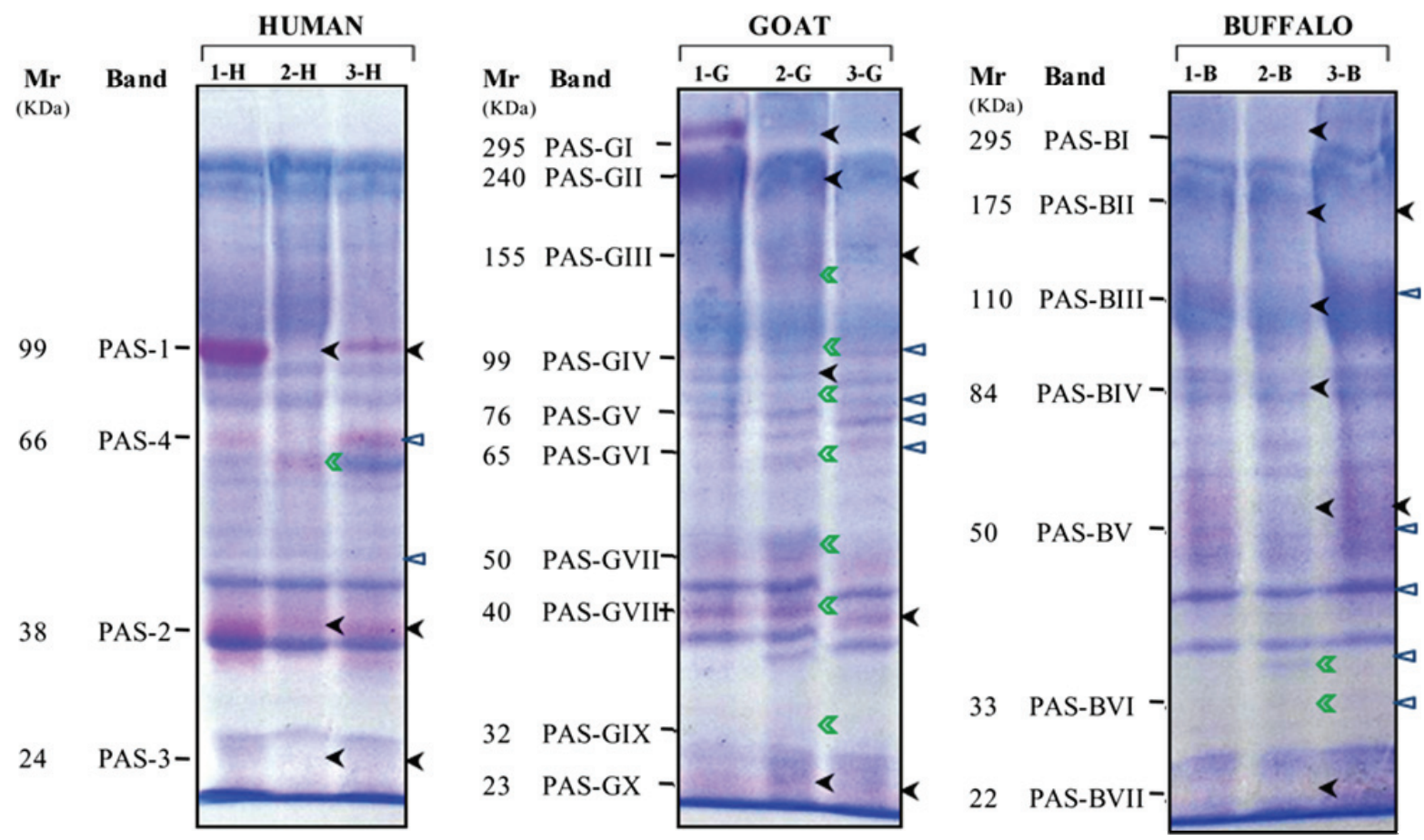

Figure 3. Analysis of membrane proteins and glycoproteins obtained from proteinase (trypsin or chymotrypsin)-treated erythrocytes by SDS-PAGE (10\% gel) followed by restaining of PAS-stained gel with CBB staining. Lane 1: untreated membranes (180 $\mu \mathrm{g}$ protein in each lane); lane 2: trypsinized membranes (180 $\mu \mathrm{g}$ protein in each lane); lane 3: chymotrypsinized membranes (180 $\mu \mathrm{g}$ protein in each lane). H, human; G, goat; B, buffalo. (see: Note in legend of Figure 1). 
cells become agglutinable with Con A (Gokhale and Mehta 1987a). Con A agglutination behaviour of proteinase and neuraminidase-treated goat and buffalo erythrocytes was studied in comparison to that of human. Con A-mediated agglutinability of mammalian erythrocytes after trypsin, chymotrypsin and neuraminidase treatment was analyzed both under microscope and by microtitre plate assay. The extent of agglutination was determined by counting number of free cells in Con A-treated samples as well as controls. Additional sugar controls were used containing Con A and a-methyl D-mannopyranoside (a sugar derivative), known to inhibit agglutination by binding to Con A with high affinity. Percentage agglutination (Fig. 7) was calculated by substituting these values in the formula as mentioned in Materials and Methods. In microtitre plate assay (Fig. 8), 0C (zero control) in the first row did not contain any Con A, while SC (sugar control) in the fourth row contained Con A $(100 \mu \mathrm{g} / \mathrm{ml})$ with inhibitory sugar ( $\alpha$-methyl D-mannopyranoside). The microtitre plate wells in second and third rows contained Con $\mathrm{A}$ as $50 \mu \mathrm{g} / \mathrm{ml}$ and $100 \mu \mathrm{g} / \mathrm{ml}$, respectively. The microtitre plate assay (Fig. 8) revealed similar results as obtained from microscopic agglutination assay. All mammalian erythrocytes did not show any agglutination in both zero and sugar controls. The mammalian erythrocytes included in this study were able to get agglutinated after trypsin $(100 \mu \mathrm{g} / \mathrm{ml})$, chymotrypsin $(250 \mu \mathrm{g} / \mathrm{ml})$ and neuraminidase $(0.01 \mathrm{unit} / \mathrm{ml})$ treatments. A significant variation in the extent of agglutination of erythrocytes was observed among these mammalian species (Fig. 7 and 8).

The extent of agglutination of trypsinized (Tr) erythrocytes was lesser in both goat (GTr) and buffalo (BTr) as compared to human (HTr) (Fig. 7A). The percentage agglutination values for Tr erythrocytes of goat and buffalo with $50 \mu \mathrm{g} / \mathrm{ml}$ Con A concentration were $\sim 17 \%$ and $54 \%$, respectively, as

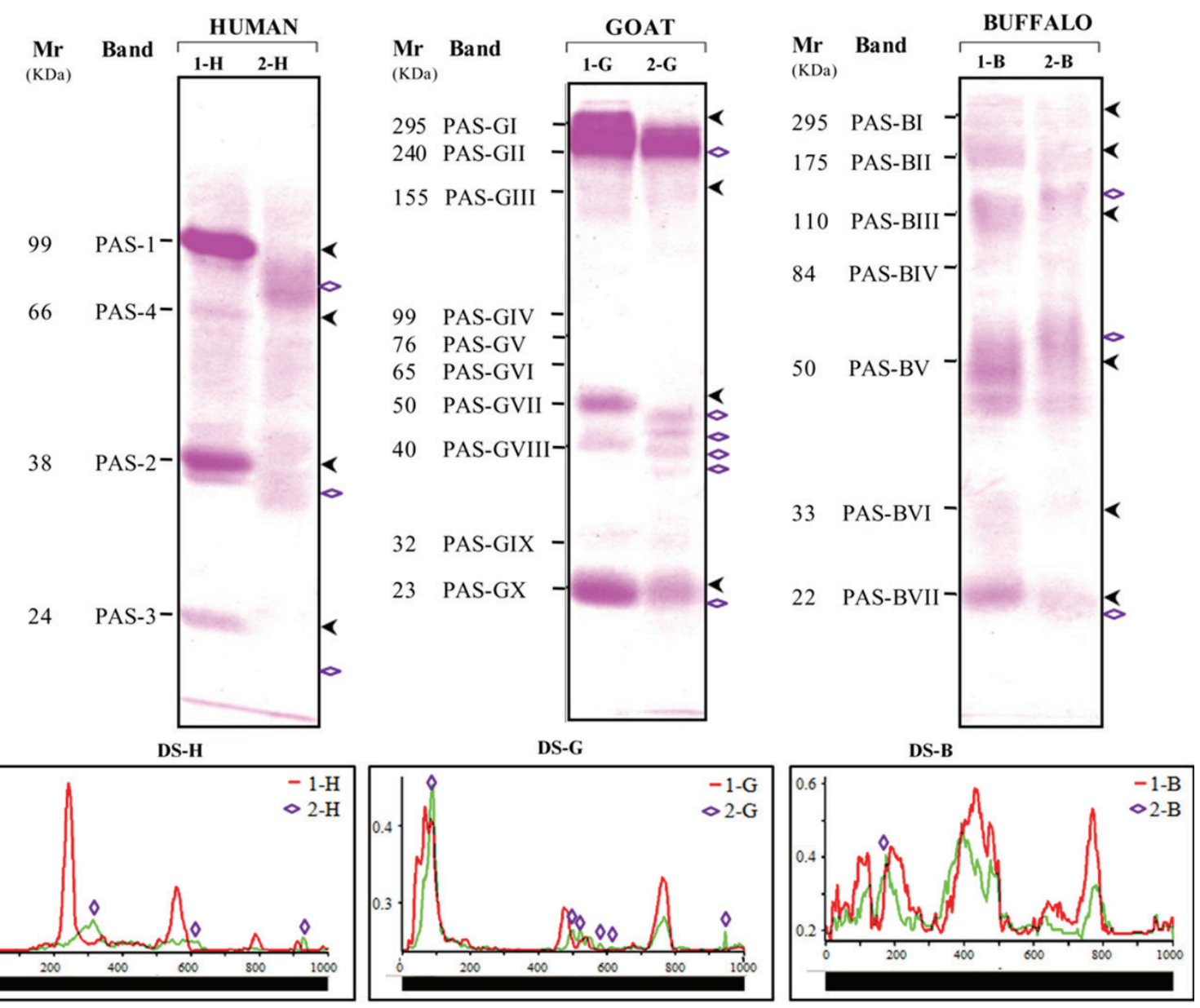

Figure 4. Analysis of membrane glycophorins obtained from neuraminidase-treated erythrocytes by SDS-PAGE (10\% gel) followed by PAS staining. Lane 1: untreated membranes (180 $\mu \mathrm{g}$ protein in each lane); lane 2: neuraminidase-treated membranes (180 $\mu \mathrm{g}$ protein in each lane). DS, densitogram; H, human; G, goat; B, buffalo. (Note: $<$ and $\diamond$ arrows indicate the proteins acted upon by neuraminidase and the new fragments generated after its action, respectively). 
compared to $62 \%$, obtained with human erythrocytes. These values of percentage agglutination of Tr erythrocytes increased to $45 \%$ for goat and $77 \%$ for buffalo, as compared to human (85\%) when Con A concentration was increased to $100 \mu \mathrm{g} / \mathrm{ml}$. The agglutination behaviour of all the three mammalian species differed significantly $(p<0.05)$ for Tr erythrocytes. While both HTr and BTr showed higher extent of agglutination, GTr erythrocytes were relatively less agglutinated. The agglutination pattern of trypsin-treated erythrocytes obtained from percentage agglutination data as well as microtitre plate assay was as follows: human $>$ buffalo $>$ goat.

The extent of agglutination of chymotrypsinized (CTr) erythrocytes was higher in goat (GCTr) and buffalo (BCTr) as compared to human (HCTr) (Fig. 7B). The values of percentage agglutination of CTr erythrocytes of goat and buffalo were $\sim 42 \%$ and $87 \%$, respectively, as compared to human (39\%) with $50 \mu \mathrm{g} / \mathrm{ml}$ Con A concentration and increased to $\sim 63 \%$ and $93 \%$, respectively, as compared to human (54\%) with $100 \mu \mathrm{g} / \mathrm{ml}$ of Con A concentration. The agglutination behaviour of CTr erythrocytes of all the three mammalian species differed significantly $(p<0.05)$. Whereas BCTr showed higher extent of agglutination, both GCTr and HCTr erythrocytes were less agglutinated. The agglutination pattern of chymotrypsin-treated erythrocytes obtained from percentage agglutination data as well as microtitre plate assay was in the order: buffalo > goat $>$ human.

The extent of agglutination of neuraminidase $(\mathrm{Nr})$-treated erythrocytes was lesser in both goat $(\mathrm{GNr})$ and buffalo $(\mathrm{BNr})$, being $\sim 43 \%$ and $61 \%$, respectively, as compared to human (67\%) with $50 \mu \mathrm{g} / \mathrm{ml}$ Con A concentration (Fig. 7C). These values were increased to $\sim 51 \%$ and $74 \%$, respectively, as compared to human (85\%) with $100 \mu \mathrm{g} / \mathrm{ml}$ Con A concentration. The agglutination behaviour of Nr-treated erythrocytes of all the three mammalian species differed significantly

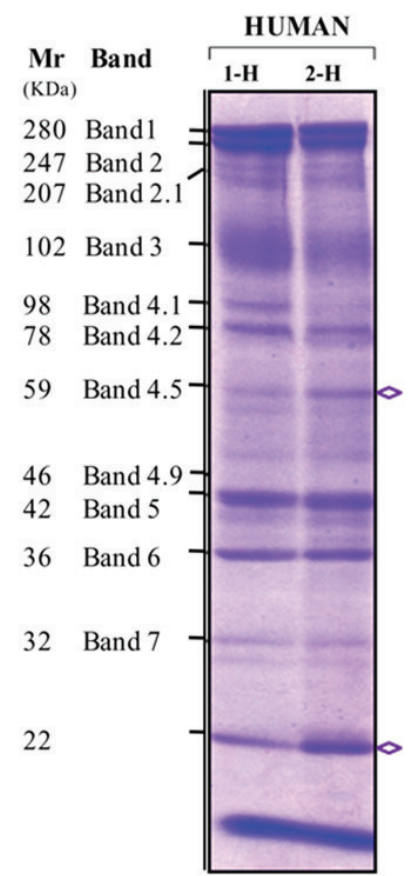

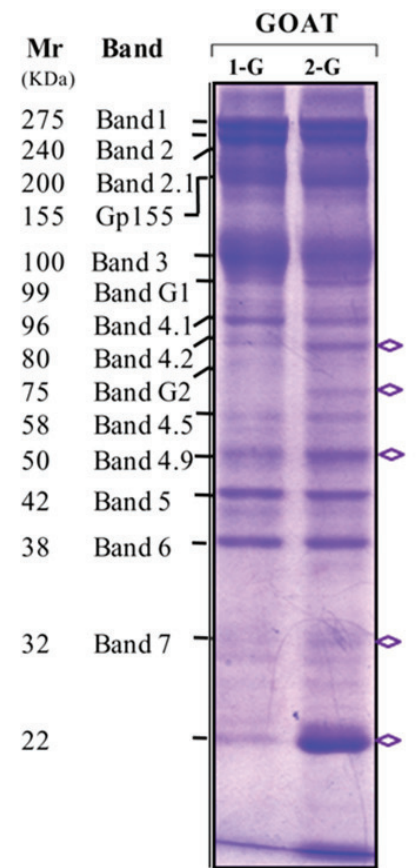

DS-G

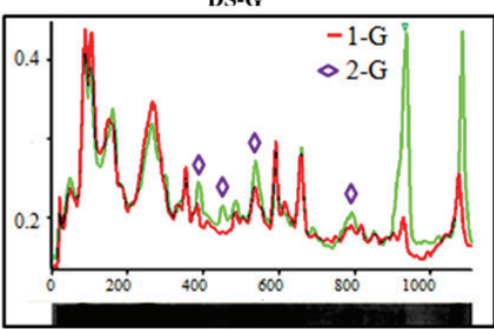

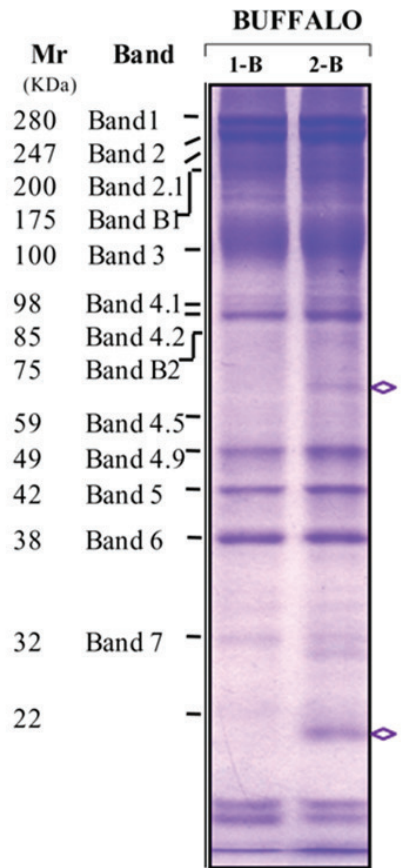

DS-B

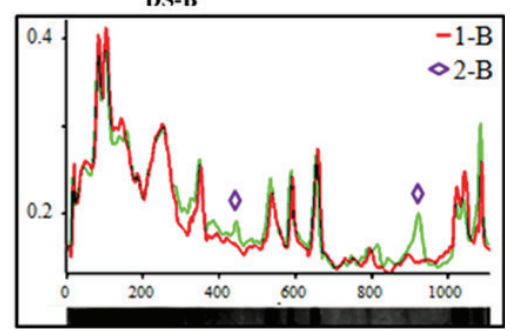

Figure 5. Analysis of membrane proteins obtained from neuraminidase-treated erythrocytes by SDS-PAGE (10\% gel) followed by CBB staining. Lane 1: untreated membranes (60 $\mu \mathrm{g}$ protein in each lane); lane 2: neuraminidase-treated membranes $(60 \mu \mathrm{g}$ protein in each lane). DS, densitogram; H, human; G, goat; B, buffalo. (Note: $\diamond$ arrows indicate the change in intensities of proteins or new fragments generated after the action of neuraminidase). 
$(p<0.05)$. Both $\mathrm{HNr}$ and $\mathrm{BNr}$ showed apparently high extent of agglutination, while GNr erythrocytes were relatively less agglutinated with the same concentration of Con A. The agglutination pattern of Nr-treated erythrocytes obtained from percentage agglutination data as well as microtitre plate assay was in the order: human > buffalo > goat.

\section{Discussion}

The proteins of human erythrocyte membrane have been extensively studied with respect to their structure and organization in last three decades (Gratzer 1981; Kakhniashvili et al. 2004). Over 250 blood group determinants are known and most of these are located on integral erythrocyte proteins and glycoproteins. The functions of some of these structures are known (Pasini et al. 2010). Glycophorins of human erythrocytes serve as receptors for viruses, bacteria and parasites (Kumar et al. 2006; Spring 2008). Cell surface features have also been studied with respect to the action of proteinases and $\mathrm{Nr}$ (Dzandu et al. 1985; Gokhale and Mehta 1987a) followed by lectin agglutinability of human erythrocytes (Nicolson 1976; Gokhale and Mehta 1987a,b,c). There are few reports available related to the structural features of erythrocyte proteins and glycoproteins of non-human mammals (Barker 1991; Matei et al. 2000). In this work attempts have been made to understand the differences in the structural features of surface-exposed membrane proteins and glycophorins of goat and buffalo in comparison to that of human erythrocytes. As reported earlier that glycophorins of erythrocyte membranes of these three species showed marked differences in their number and sizes when visualized by sialoglycoprotein-specific PAS staining (Sharma and Gokhale 2011). Sialic acid residues of glycophorins exposed to exterior face contribute to the cell surface charge of erythrocytes and any variation in the sialic acid content as indicated by PAS-stained gels would be responsible for differences in the cell surface charge among these species.

In this study, action of proteinases viz. trypsin and chymotrypsin, on goat and buffalo erythrocytes followed by analysis of their membranes by SDS-PAGE indicated that there was a prominent action of trypsin on goat and chymotrypsin on buffalo erythrocyte membrane proteins (stained with CBB; Fig. 1). There was no action of trypsin on buffalo and chymotrypsin on goat erythrocyte membrane proteins as indicated by CBB-stained gel. GTr erythrocyte membranes showed three new fragments, one of these was identified as $57 \mathrm{kDa}$ fragment of gp155 glycoprotein (Inaba and Maede

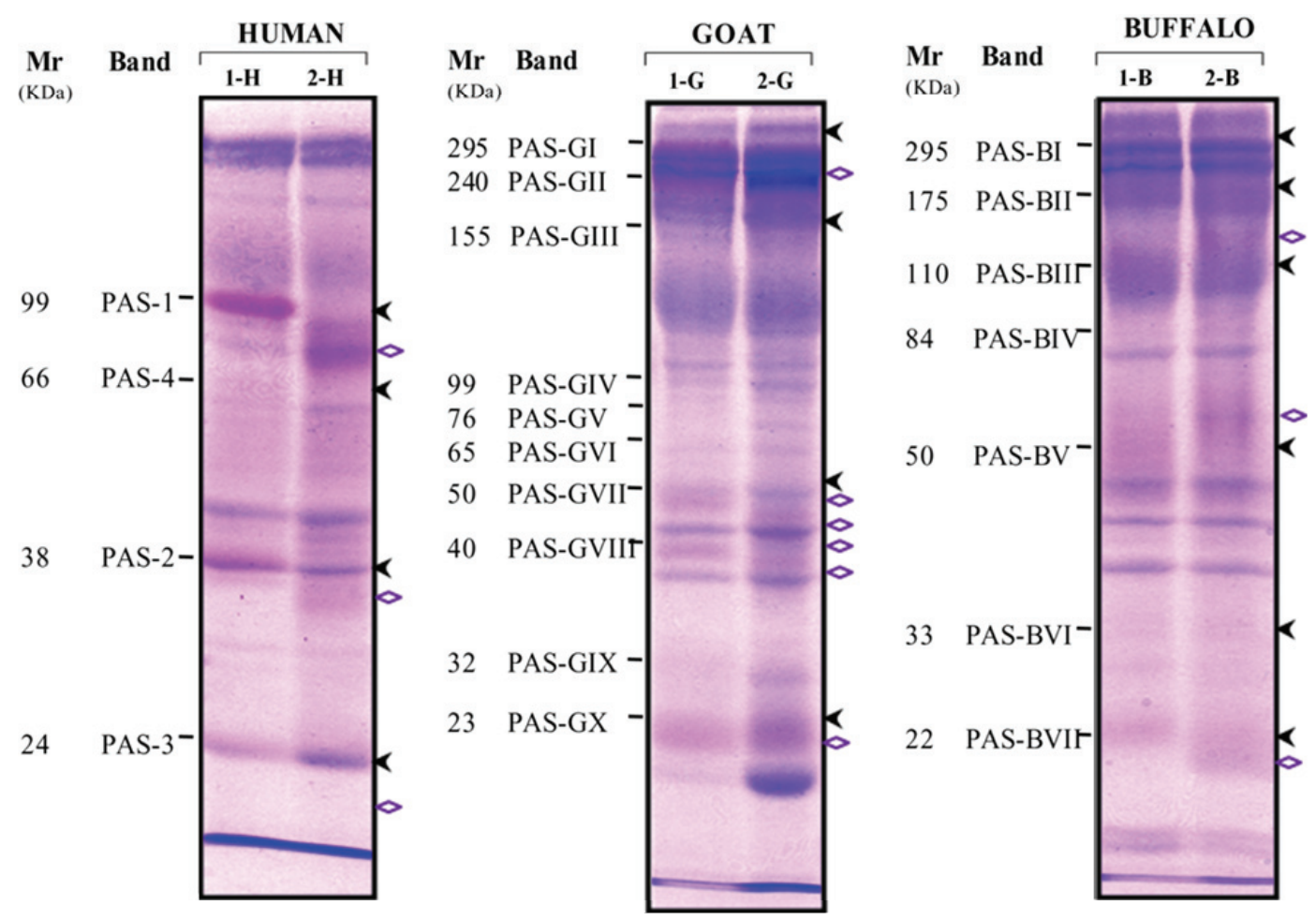

Figure 6. Analysis of membrane proteins and glycophorins obtained from neuraminidase-treated erythrocytes by SDS-PAGE (10\% gel) followed by restaining of PAS-stained gel with CBB staining. Lane 1: untreated membranes (180 $\mu \mathrm{g}$ protein in each lane); lane 2: neuraminidase-treated membranes (180 $\mu \mathrm{g}$ protein in each lane). H, human; G, goat; B, buffalo. (see: Note in legend of Figure 4). 
A

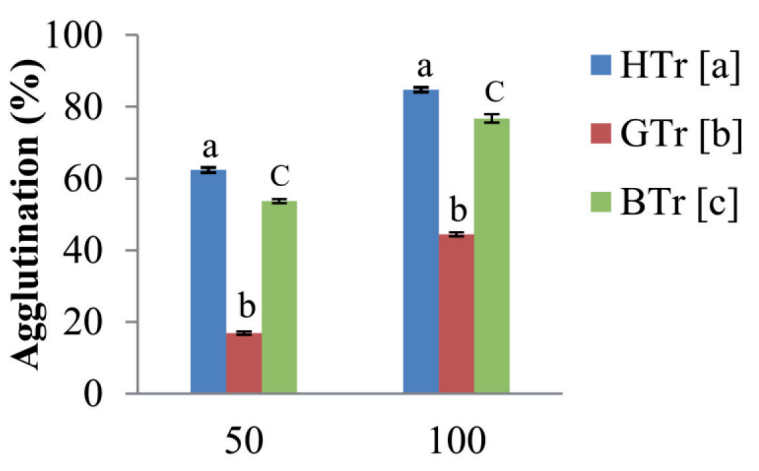

$\operatorname{Con} \mathbf{A}(\mu \mathrm{g} / \mathrm{ml})$

B

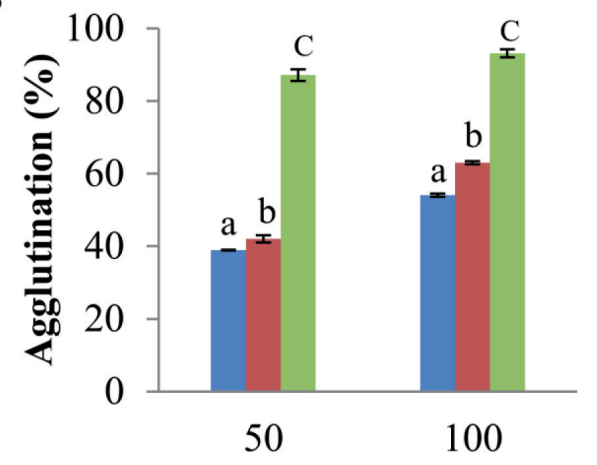

$\operatorname{Con} \mathbf{A}(\mu \mathrm{g} / \mathrm{ml})$

C

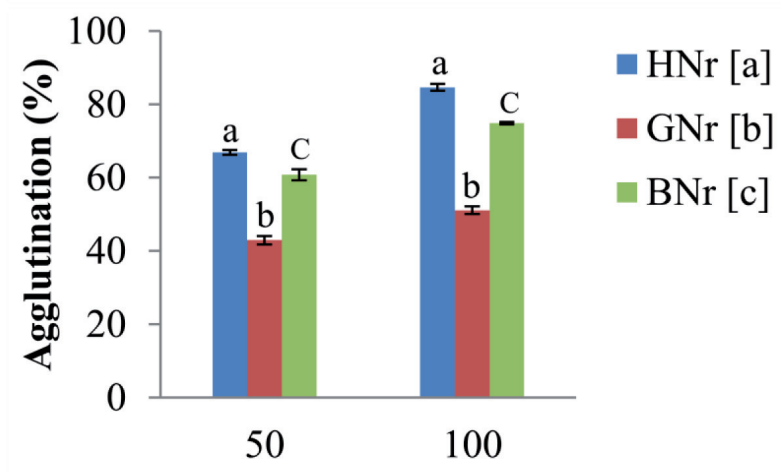

Con A $(\mu \mathrm{g} / \mathrm{ml})$

Figure 7. Con A-mediated agglutinability of human $(\mathrm{H})$, goat (G) and buffalo (B) erythrocytes treated with different enzymes (determined by microscopic agglutination assay). Graphs A, B and $\mathrm{C}$ are showing percent agglutination of trypsinized (Tr), chymotrypsinized (CTr) and neuraminidase (Nr)-treated erythrocytes, respectively. Con A concentration used were 50 and $100 \mu \mathrm{g} / \mathrm{ml}$ The data are mean of \pm S.E.M. $(p<0.05 ; n=5)$. The upper symbols with small letters indicate the differences in Con A agglutinability among three mammalian species at Con A concentration of 50 and $100 \mu \mathrm{g} / \mathrm{ml}$, respectively.
1988). This probably indicated that there were some lysine and/or arginine residues of proteins exposed on cell surface for trypsin action in goat which were not available in case of human and buffalo erythrocytes. Similarly, chymotrypsin showed action on aromatic/hydrophobic amino acid residues of human and buffalo erythrocytes but not on goat erythrocyte surface proteins. There are reports about the action of chymotrypsin on band 3 of human erythrocytes exposed to cell surface (Markowitz and Marchesi 1981). BCTr erythrocyte surface proteins showed three new fragments of $\mathrm{Mr} 63 \mathrm{kDa}, 50 \mathrm{kDa}$ and $37 \mathrm{kDa}$. Action of proteinases on glycophorins of human erythrocyte membranes were in agreement with previous literature (Dzandu et al. 1985; Gokhale and Mehta 1987a). Trypsin showed action on many glycophorins of human and buffalo erythrocytes. On the other hand, chymotrypsin did show partial or no action on these glycophorins. In the case of goat erythrocytes, trypsin and chymotrypsin both showed the action on many glycophorins i.e. PAS GI to GIV. The only difference in the action of these two enzymes was that trypsin showed a partial while chymotrypsin showed a drastic action on goat erythrocyte glycophorins. The Nr-treated goat and buffalo erythrocyte membranes showed decrease in PAS band intensities or change in their positions on the gel due to the removal of sialic acid residues. This alteration in the PAS banding pattern confirmed the action of $\mathrm{Nr}$ on sialic acid residues of glycophorins exposed to cell surface, similar to human erythrocytes (Gahmberg and Andersson 1982).

The mammalian erythrocytes became agglutinable with Con A after treatment with proteinases or neuraminidase. The actions of the enzymes on band 3 did not correlate with their abilities to increase the Con A agglutinability as chymotrypsin-treated human erythrocytes (showing marked action on band 3) showed minimum agglutination among these three species. On the other hand, CTr buffalo erythrocytes (with no action on band 3 ) showed maximum agglutination with Con A. It is possible that the ability of Con A to promote agglutination was related to the extent of degradation of glycophorins, specifically PAS bands GI and GII of goat, and BI, BIII and BV of buffalo erythrocytes. As indicated by PAS-stained gels, a direct correlation was found between degradation of glycophorins and Con A agglutinability similar to human erythrocytes (Gahmberg and Andersson 1982; Gokhale and Mehta 1987a). Action of Nr specifically demonstrated the negative role of cell surface sialic acids on Con A agglutinability, similar to human erythrocytes. Since glycophorins carry a very large proportion of the total sialic acids of erythrocyte membrane, their removal would decrease the overall surface charge and thus facilitate the approach and interaction between the cells during agglutination. In fact, this is also a requirement since for stable interaction; the cells have to come within $0.5 \mathrm{~nm}$ in the vicinity of each other, which is initially impossible because of the potential 
A

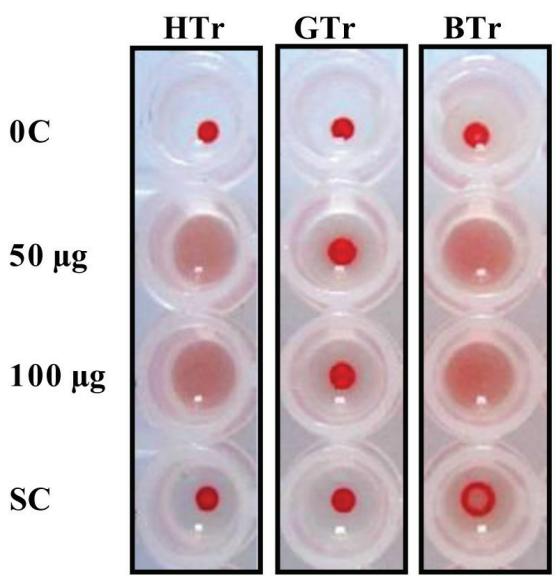

B

0C

$50 \mu \mathrm{g}$

$100 \mu \mathrm{g}$

SC
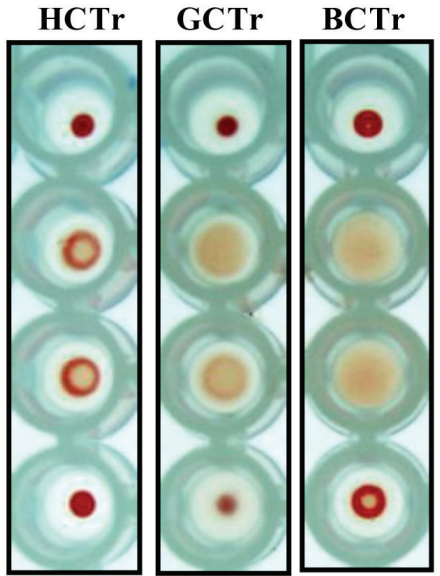

C

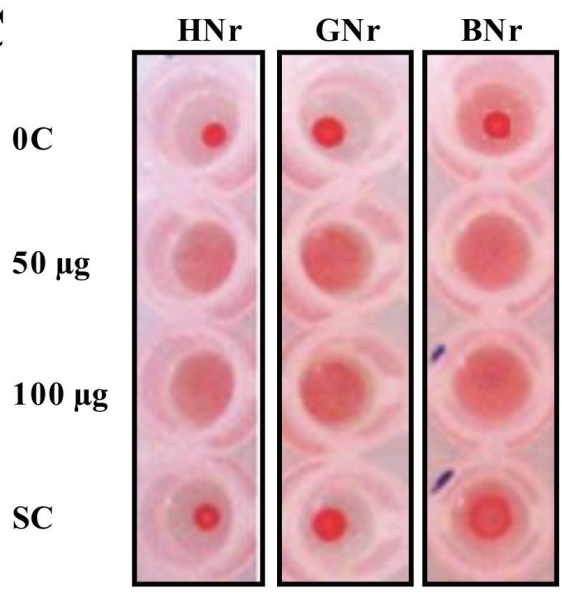

Figure 8. Microtitre plate assay of Con A-mediated agglutinability of human $(H)$, goat $(G)$ and buffalo (B) erythrocytes treated with different enzymes. Figures $\mathrm{A}, \mathrm{B}$ and $\mathrm{C}$ show agglutination assay of trypsinized (Tr), chymotrypsinized (CTr) and neuraminidase $(\mathrm{Nr})$-treated erythrocytes respectively. Con A concentration used were 50 and $100 \mu \mathrm{g} / \mathrm{ml}$. 0C (zero control without Con A), SC (sugar control with $100 \mu \mathrm{g} / \mathrm{ml}$ Con A and $0.05 \mathrm{M}$ a-methyl D-mannopyranoside). energy repulsion barriers. In order to overcome this, sensing of surface regions having lower than average charge density would be needed (Weiss 1973). As Con A is known to have maximum affinity for binding to mannose and glucose (Goldstein and Hughes 1978), these sugars determine the number of Con A binding sites on the erythrocyte cell surface. Therefore, another possible reason for enhancement of agglutination may be the exposure of such Con A binding sites, which were hidden prior to the enzyme treatments. Present study is important for understanding the structural features of goat and buffalo erythrocyte membrane proteins especially with respect to differences in the characteristics as compared to human erythrocytes. It will be helpful in investigating the surface architecture of glycophorins of goat and buffalo erythrocyte membranes.

Acknowledgements. This work was supported by a grant from the University Grant Commission - Major Research Project [No. F-37-138/2009 (SR)] New Delhi, India. We also thank all those who donated blood for this study.

Conflicts of interest: The authors confirm that there are no conflicts of interest.

\section{References}

Abu J. C., Tieslau C., Lankester A. (1963): Reactions of normal and tumor cell surfaces to enzymes. I. Wheat-germ lipase and associated mucopolysaccharides. Proc. Natl. Acad. Sci. U.S.A. 50, 613-619 http://dx.doi.org/10.1073/pnas.50.4.613

Ali M. K., Tayyab S. (2001): Effect of phospholipase C, trypsin and neuraminidase on binding of bilirubin to mammalian erythrocyte membranes. Comp. Biochem. Physiol. 129, 355-362 http://dx.doi.org/10.1016/S1095-6433(00)00353-6

Anderson R. A., Paquette S., Lovrien R. (2002): Lectin-erythrocyte interaction with external transmembrane glycophorin saccharides controlling membrane internal cytoskeleta. J. Agric. Food Chem. 50, 6599-6604 http://dx.doi.org/10.1021/jf020261n

Barker R. N. (1991): Electrophoretic analysis of erythrocyte membrane proteins and glycoproteins from different species. Comp. Haematol. Int. 1, 155-160 http://dx.doi.org/10.1007/BF00515663

Burger M. M. (1970): A difference in the architecture of the surface membrane of normal and virally transformed cells. Proc. Natl. Acad. Sci. U.S.A. 62, 994-1001 http://dx.doi.org/10.1073/pnas.62.3.994

Dzandu J. K., Deh M. E., Wise G. E. (1985): A re-examination of the effects of chymotrypsin and trypsin on the erythrocyte membrane surface topology. Biochem. Biophys. Res. Commun. 126, 50-58 http://dx.doi.org/10.1016/0006-291X(85)90569-8

Fairbanks G., Steck T. L., Wallach D. F. H. (1971): Electrophoretic analysis of the major polypeptides of the human erythrocyte membrane. Biochemistry 10, 2606-2617 http://dx.doi.org/10.1021/bi00789a030 
Findlay J. B. (1974): The receptor proteins for concanavalin A and Lens culinaris phytohemagglutinin in the membrane of the human erythrocyte. J. Biol. Chem. 249, 4398-4403

Gahmberg C. G., Andersson L. C. (1982): Role of sialic acid in the mobility of membrane proteins containing O-linked oligosaccharides on polyacrylamide gel electrophoresis in sodium dodecyl sulfate. Eur. J. Biochem. 122, 581-586 http://dx.doi.org/10.1111/j.1432-1033.1982.tb06478.x

Gokhale S. M., Mehta N. G. (1987a): Glycophorin A interferes in the agglutination of human erythrocytes by concanavalin A. Biochem. J. 241, 505-511

Gokhale S. M., Mehta N. G. (1987b): Concanavalin A-agglutinability of membrane-skeleton-free vesicles and aged cellular remnants derived from human erythrocytes. Biochem. J. 241, 513-520

Gokhale S. M., Mehta N. G. (1987c): Concanavalin A binding to human erythrocytes leads to alterations in properties of the membrane skeleton. Biochem. J. 241, 521-525

Goldstein J. J., Hughes C. E. (1978): The lectins: carbohydratebinding proteins of plants and animals. Adv Carbohydr. Chem. Biochem. 35, 127-340 http://dx.doi.org/10.1016/S0065-2318(08)60220-6

Gratzer W. B. (1981): The red cell membrane and its cytoskeleton. Biochem. J. 198, 1-8

Hamasaki N., Okubo K., Kuma H., Kang D., Yae Y. (1997): Proteolytic cleavage sites of band 3 protein in alkali-treated membranes: Fidelity of hydropathy prediction for band 3 protein. J. Biochem. 122, 577-585 http://dx.doi.org/10.1093/oxfordjournals.jbchem.a021792

Hanahan D. J., Ekholm J. E. (1974): The preparation of red cell ghosts (membranes). Methods Enzymol. 31, 168-172 http://dx.doi.org/10.1016/0076-6879(74)31018-X

Haskovec C., Kinkor M. (1976): Interaction of lectins with surface membrane receptors of animal cells. Factors responsible for agglutinability of human, rabbit, and sheep erythrocytes with concanavalin A. Folia Biol. (Praha) 22, 225-234

Inaba M., Maede Y (1988): A new major transmembrane glycoprotein, gp155, in goat erythrocytes. J. Biol. Chem. 263, 17763-17771

Jennings M. L., Nicknish J. S. (1985): Localization of a site of intermolecular cross-linking in human red blood cell band 3 protein. J. Biol. Chem. 260, 5472-5479

Kakhniashvili D. G., Bulla L. A., Goodman S. R. (2004): The human erythrocyte proteome. Mol. Cell. Proteomics 3, 501-509 http://dx.doi.org/10.1074/mcp.M300132-MCP200

Kapito R. R., Lodish H. (1985): Primary structure and transmembrane orientation of the murine anion exchange protein. Nature 316, 234-238 http://dx.doi.org/10.1038/316234a0

Kumar K. A., Singh S., Babu P. P. (2006): Studies on the glycoprotein modification in erythrocyte membrane during experimental cerebral malaria. Exp. Parasitol. 114, 173-179 http://dx.doi.org/10.1016/j.exppara.2006.03.009

Laemmli U. K. (1970): Cleavage of structural proteins during the assembly of the head of bacteriophage T4. Nature 227, 680-685 http://dx.doi.org/10.1038/227680a0
Lowry O. H., Rosebrough N. J., Farr A. L., Randall R. J. (1951): Protein measurement with the Folin phenol reagent. J. Biol. Chem. 193, 265-275

Makino S., Moriyama M., Kitahara T., Koga S. (1984): Proteolytic digestion of band 3 from bovine erythrocyte membranes in membrane-bound and solubilized states. J. Biol. Chem. 95, 1019-1029

Markowitz S., Marchesi V. T. (1981): The carboxyl-terminal domain of human erythrocyte band 3. J. Biol. Chem. 256, 6463-6468

Matei H., Frentescu L., Benga Gh. (2000): Comparative studies of the protein composition of red blood cell membranes from eight mammalian species. J. Cell. Mol. Med. 4, 270-276 http://dx.doi.org/10.1111/j.1582-4934.2000.tb00126.x

Mehta N. G., Gokhale S. M., Pestonjamasp K. N. (1988): Endogenous factors determining the agglutinability of erythrocytes with concanavalin A. Ind. J. Biochem. Biophys. 25, 14-19

Moriyama R., Nagatomi Y., Hoshino F., Making S. (1994): Amino acid sequences around exofacial proteolytic cleavage sites of band 3 from bovine and porcine erythrocytes. Int. J. Biochem. 26, $133-137$ http://dx.doi.org/10.1016/0020-711X(94)90206-2

Nicolson G. L. (1976): Trans-membrane control of the receptors on normal and tumor cells. Surface changes associated with transformation and malignancy. Biochim. Biophys. Acta 458, $1-72$

Okamura M., Yokoyama N., Takabatake N., Okubo K., Igarashi I. (2007): Modification of host erythrocyte membranes by trypsin and chymotrypsin treatments and effects on the in vitro growth of bovine and equine Babesia parasites. J. Parasitol. 93, 208-211 http://dx.doi.org/10.1645/GE-914R.1

Pasini E. M., Lutz H. U., Mann M., Thomas A. W. (2010): Red blood cell (RBC) membrane proteomics - Part II: Comparative proteomics and RBC patho-physiology. J. Proteomics 73, 421-435 http://dx.doi.org/10.1016/j.jprot.2009.07.004

Pestonjamasp K. N., Mehta N. G. (1991): Relationship between the concanavalin A-agglutinability and deformability of human erythrocytes. Biochim. Biophys. Acta 1073, 341-346 http://dx.doi.org/10.1016/0304-4165(91)90141-3

Rashid H., Owais M., Tayyab S. (2001): Bilirubin binding to normal and modified human erythrocyte membranes: Effect of phospholipases, neuraminidase, trypsin and $\mathrm{CaCl} 2$. Mol. Cell. Biochem. 228, 15-23

http://dx.doi.org/10.1023/A:1013300106220

Sharma S., Gokhale S. M. (2011): Sialoglycoproteins of mammalian erythrocyte membranes: A comparative study. Asian Aust. J. Anim. Sci. 24, 1666-1673 http://dx.doi.org/10.5713/ajas.2011.11162

Spring F. A. (2008): Characterization of blood-group-active erythrocyte membrane glycoproteins with human antisera. Transfus. Med. 3, 167-178 http://dx.doi.org/10.1111/j.1365-3148.1993.tb00112.x

Weiss L. (1973): Neuraminidase, sialic acid and cell interactions. J. Natl. Cancer Inst. 50, 3-19

Received: January 25, 2012

Final version accepted: June 13, 2012 